\title{
UNDERSTANDING REGIONAL EFFECTS ON CLIMATE CHANGE AND MULTIDISCIPLINARY APPROARCH FOR COPING STRATEGIES - CASE STUDY AT RURAL VILLAGE IN SUB-SAHARAN AFRICA -
}

\author{
M. Yoshimura ${ }^{1,}$, M. Yamashita ${ }^{2}$ \\ ${ }^{1}$ PASCO Corporation, PASCO Research Institute, 2-8-10 Higashiyama, Meguro-ku, Tokyo, Japan - mairtu1698@pasco.co.jp \\ 2 Tokyo University of Agriculture and Technology, Faculty of Agriculture and Women's Future Developing Organization, 3-5-8 \\ Saiwai-cho, Fuchu, Tokyo, Japan -meguyama@cc.tuat.ac.jp
}

Commission III, WG III/10

KEY WORDS: climate change, shock, vulnerability, coping strategies, resilience, diversity

\begin{abstract}
:
This paper describes on understanding the regional effects on global climate change and subsistence farmers' coping strategies through our field investigation and multidimensional data analysis from the resilience point of view. The major research question of this study is to understand what actions villagers took as the coping strategy against the heavy rainfall shock caused by climate change. Our research interest is how geospatial information technique can contribute to this research question. The study area is located in Sinazongwe district, Southern province of Zambia. As for the field investigation, we set the study sites A, B and C where are located in the lower terrace, middle escarpment and upper terrace, respectively. In the rainy season of 2007/2008, our study site had a heavy rainfall and many crop fields were damaged. In this crop year, the annual rainfalls in site A and C were $1442 \mathrm{~mm} / \mathrm{year}$ and $1332 \mathrm{~mm} /$ year respectively. This is about two times different with the long term average of rainfall $694.9 \mathrm{~mm} / \mathrm{year}$ in Sinazongwe district. It is confirmed that approximately $20 \%$ of crop fields were damaged by heavy rainfall through our field investigation. It was so severe negative consequences for all of villages because about $80 \%$ of whole damaged crop fields were maize fields. Maize is staple food in this region. Here, we have analysed and discussed how villagers cope from the serious damage of crops. The maize harvest varies every year depending on rainfall and topographic position. If a farmer possesses maize fields at various topographic positions, they can avoid severe negative consequences of climate variability such as drought or heavy rainfall. However, not all farmers have access to fields at various topographic positions. It is important to know where each household's characteristics when we consider their strategy of livelihood for climate variabilities. Through this study, we confirmed the way to strengthen resilience of subsistence farmers as follows: it is necessary to prepare variable crops and emergency food stock with not only diverse but also composite social institution. The resilient society seems to be the society with insurance such as adaptation ability against environmental shock caused by climate change. From the agricultural production point of view, both diversity and yield ability are also important.
\end{abstract}

\section{INTRODUCTION}

\subsection{Vulnerability and Resilience}

The environmental resources such as vegetation and soil are vulnerable to human activities. In order to solve these global environmental issues, a key factor is a recovery from, or a resilience of human society and ecosystems to, the impacts of environmental variability. The social recognition as the sustainable community against natural disasters or abnormal weathers has strengthened in recent years. The general concept of vulnerability and resilience expresses the multidimensionality of disasters by focusing attention on the totality of relationships between the social situations and environmental forces, produces a disaster. The term of resilience is becoming to be known as the common key in order to consider the present state of sustainable society.

In the field of ecology, the ecological resilience is defined as the recovery time required for the disturbed ecosystem to return to the initial equilibrium before being disturbed. On the other hand, it is defined as the coping ability of communities or groups against the stresses or disturbances for social, institutional and environmental changes in social science. The resilience is the opposite concept of vulnerability and used as the meaning of spontaneous recovery. Thus it is whole coverage concept over the ability of recover, toughness, pliancy and resistance. The resilience is also defined as abilities of a society, system or organization with toughness to be adapted or recovered smartly against extreme shock.

\subsection{Objectives}

The final goal of this study is to understand subsistence farmers' vulnerability and resilience on regional impact of climate change. For this final goal, we focused on the topic of heavy rainfall event as an environmental shock which occurred in December 2007 at southern province of Zambia. Zambia is one of Sub-Saharan Africa countries and including Semi-Arid Tropics (SAT) climate zone.

In this study, we conducted as follows;

1) to investigate impact of environmental variability on agricultural production,

2) to analyse factors determining the ability of households to recover from environmental shock,

3) to consider the way to strengthen the resilience of subsistence farmers to future environmental shock.

4) to clarify an effectiveness of geospatial information technique utilization for this multidisciplinary research approach. 


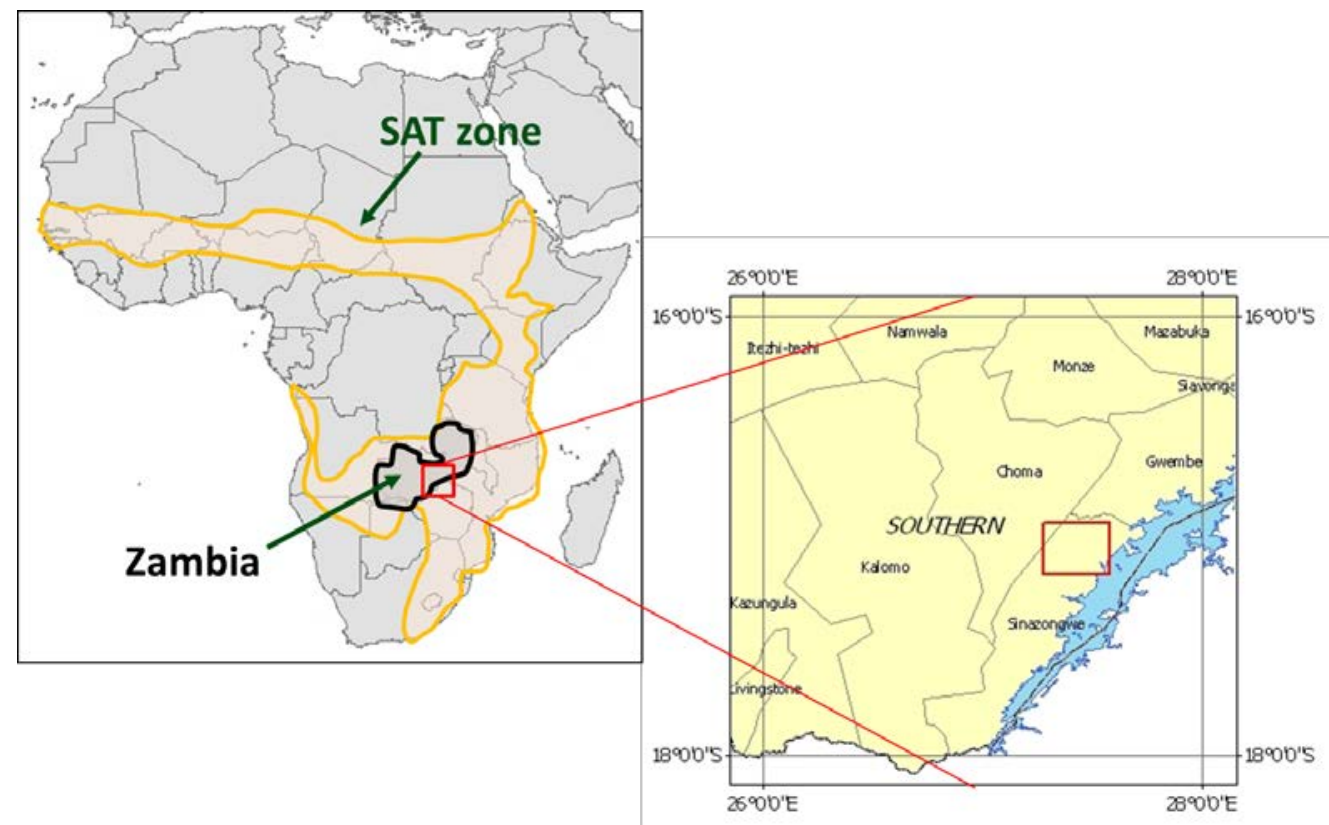

Fig.1 Location of Zambia and Study Site

\section{STUDY SITE}

\subsection{Location and Climate of Zambia}

A vicious cycle of poverty and environmental degradation is a major issue of global environmental problems. Especially in SAT climate zone including Sub-Saharan Africa and South Asia where the majority of the poor is concentrated, poverty and environmental degradation is widely prevalent. People in this area largely depend on rain-fed agricultural production systems and their livelihoods are vulnerable to environmental variability. According to this situation, we selected southern province, Zambia as our study site. Figure 1 shows the location of Zambia in African continent and the location of southern province as our study site in Zambia. The Lake Kariba with lowest altitude as one of the world biggest artificial lakes has made after Kariba dam construction in 1959 at the southern edge of Zambia (right of figure in Fig.1) and the boundary between Zimbabwe.

\subsection{Regional Characteristics and Study Sites Setting}

Zambia is located at south part of Sub-Saharan Africa countries. The most of land in Zambia is located at high land with 700$2,000 \mathrm{~m}$ altitude and belonging to the humid temperate or tropical savanna climate. In this region, there is cool dry season in the period from May to August, hot dry season is from September to November and rainy season is from December to April respectively. People's livelihoods are mainly farming. However most of them are small subsistence farmers and more than $80 \%$ farmers in Zambia are cultivating white maze. The white maize is staple food in this region. Its cultivation also depends on the rain-fed agriculture system and is vulnerable to environmental varieties. Therefore Zambia is often facing the food crisis at national level in every few years when drought happened.

In order to understand subsistence farmers s' resilience on regional impact of climate change, we set three study sites namely sites A, B and C. They are spread over the slope adjoining Lake Kariba: Site A is located on the lower terrace of the slope on the lakeshore; Villagers in site A had moved in the early 1960's after the Kariba dam construction; Site B is located on the middle escapement between site $\mathrm{A}$ and $\mathrm{C}$; Villagers in site B has moved since 1980's; Site C is on the upper terrace of the slope on the southern edge of the Zambia plateau; All villages in site $\mathrm{C}$ are commonly older than site $\mathrm{A}$ and $\mathrm{B}$. The target of the field survey are total five villages (ASm and ASn in site A, BKa and BCh in site B and CSa in site C) and 195 households. This region in southern province of Zambia is known as the most drought-prone zone in this country with annual precipitation of less than $800 \mathrm{~mm}$.

\subsection{Climate Varieties and Shocks}

Fig. 2 shows the rainfall variability at Choma of southern province near study site in the period from 1950 to 2009. This graph is drawn by precipitation data which observed at Choma metrological station. The bar graph is the deviation against mean annual precipitation from October to April and the line graph is December precipitation.

As the general trend of 60 years rainfall variability, the mean annual precipitation is calculated as $797 \mathrm{~mm}$. From this graph, several environmental shocks which are corresponding triangles namely drought damage years are recognized with minus deviation. Especially in recent years, it seems to be occurred with increased frequency. As the other environmental shock is heavy precipitation years which are several peaks on line graph. The rainfall in December 2007 is confirmed to be the magnitude of once in 30 years.

On the other hands, we had started the data collection as our field investigation at site A, B and C sample households since November 2007 at the beginning of the 2007/08 rainy season. At the beginning of our field investigation, in December 2007, a heavy rainfall occurred at our study sites. And it caused many disasters such as destroying cultivation fields at most of study sites. This was the rare environmental event in the droughtprone zone of Zambia and caused serious damage to agricultural production. Hence, we focus on this heavy rain shock and analyze using field survey data in order to know the heavy rain shock and the process of recover from it. 


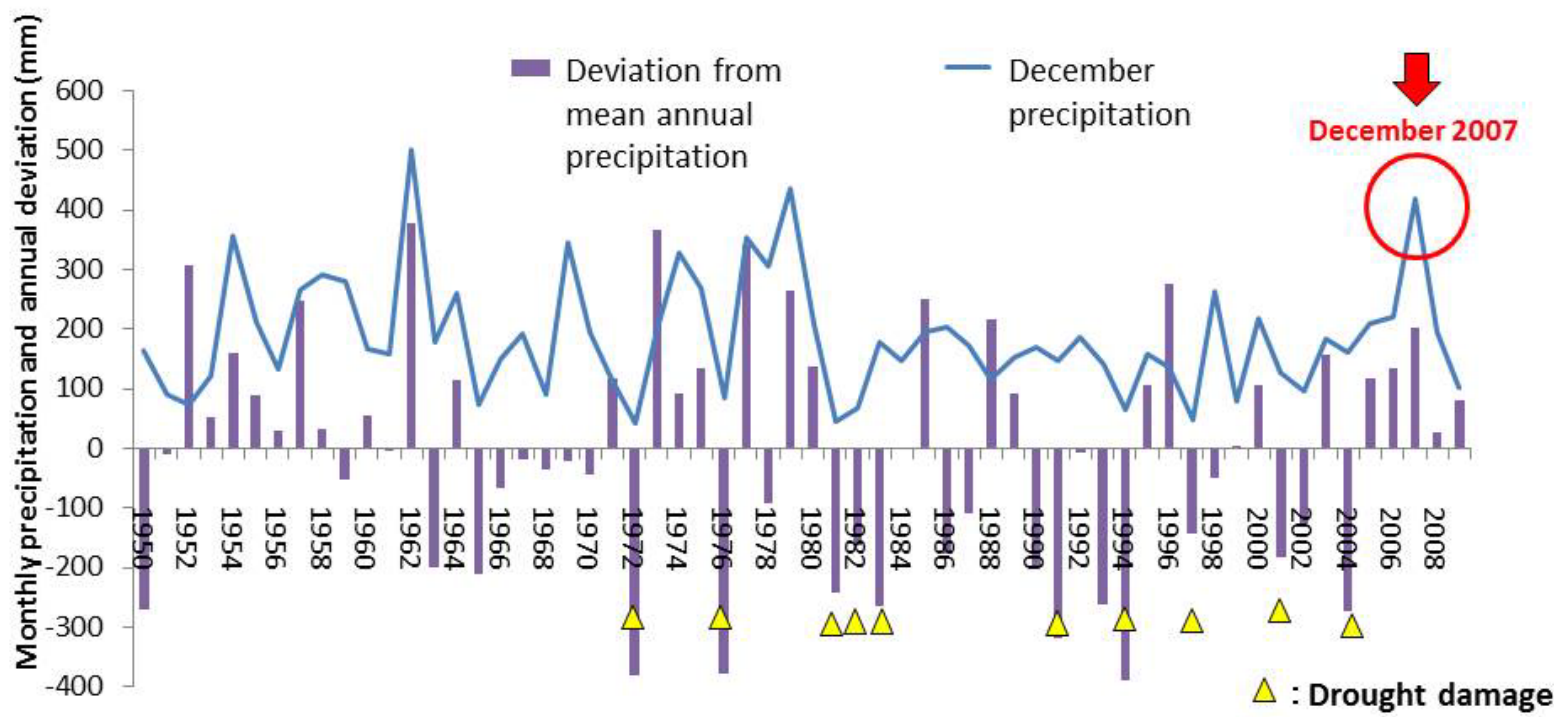

Fig. 2 Rainfall Varievility at Choma of Souyhern Province, Zambia (1950-2009)

\section{FIELD INVESTIGATION AND DATA ANALYSIS}

In order to know the actual circumstances at each study site and each village, we conducted the field investigation which consists of household survey, crop allocation survey and topographic survey. Whole gathered survey data were converted and integrated as the multidimensional data which possible to manipulate under the same map coordinate system. And aerial photographs and satellite imageries were also utilized to know the topographical characteristics. Their imageries are also overlaid with same map coordinate system. In the data analysis, we focused on the interactions of household varieties, crop allocation patterns and topographical characteristics in order to understand subsistence farmers s' coping strategies as their vulnerability and resilience on regional impact of climate change.

\subsection{Topographic Survey}

To understand topographical characteristics of our study site, the Digital Elevation Model (DEM) is the most effective. Therefore we gathered aerial photographs archived at the survey department of Zambia. Gathered aerial photographs had been taken after the independence of Zambia with different scale of about 1:30,000 in 1965, 1970, 1980 and 1991. However, photographs in 1965 did not cover over with our study site. Thus 90 sheets of aerial photographs in 1970, 67 sheets in 1980 and 72 sheets in 1991 were utilized to our study. We generated DEM with $2.5 \mathrm{~m}$ grid and orthographic aerial photos imageries with the large scale by applying stereo matching and related processes for mentioned aerial photographs taken in 1991 with a scale of approximately 1:30,000. However, because an area around site C was not covered completely, we utilized a stereo pair of ALOS/PRISM images taken on 2008/10/24 from nadir, forward and backward views. We also collected ASTER Global Digital Elevation (GDEM) with $30 \mathrm{~m}$ grid, more than
30 imageries of Landsat series, Terra/ASTER, ALOS/AVNIR-2 and PRISM for the land surface monitoring. At the same time, the geometric correction was carried out for all of satellite imageries. Using generated DEM, we calculated slop and classified it as slop hazard data with 7 levels. Furthermore we also summarised slop hazard data and DEM as statistics of each crop field.

\subsection{Household Survey}

In order to understand households' coping strategies against climate variations, the interview was conducted as the household survey. This interview was carried out by an enumerator using questionnaire to obtain personal information about each respondent such as field names, topography, soil type, crops, cultivated varieties and types of fertilizer related to household, agricultural production, cash income, and consumption.

We assumed the cash income is selling maize, cotton, vegetables and livestock, fisher and piece-work etc. We have had interviews about the income depend on both agricultural and non-agricultural activities for all households in site A, B and C in 2007 and 2008 and calculated their activities changes by comparison with before /after the damage of heavy rainfall. The total numbers of households were 195: ASm in site A was 36; ASn in site A was 38; BCh in site B was 23; BKa in Site B was 15; CSa in site C was 83.

\subsection{Crop Allocation Survey}

The crop field distribution at the village level for one year shows household's activities related people's livelihood. In this study, the crop allocation map was generated to understand people's livelihood from year to year. Field investigation for crop allocation map was performed for 195 households in ASm and ASn (site A), BKa and BCh (site B) 
and CSa in (site C) villages during the rainy season of 2007/2008 and the dry season of 2008. To generate the crop allocation map, we used a portable Global Navigation Satellite System (GNSS) instrument to measure boundaries at a sub-field level that recognized different crops at site A, B and $\mathrm{C}$. In addition, the boundaries of crop fields and attributes which obtained in household survey were converted to the general geographic information (GIS) data format with a Shape file (.shp). This case dealt with heavy rainfall shock and recover from it. When we measured boundaries of crop fields, we set classification code and its description of each crop field as attribute information of the crop allocation map in GIS data. Furthermore we measured boundaries of damaged crop fields and investigated its conditions after damage. This identification of damaged crop fields was defined by an enumerator. When they recognized damaged crop fields through the interview of household, they measured boundaries by GNSS instrument, again. And these data was converted to GIS data. The serious damaged crop fields means that is impossible to be harvested

\section{RESULTS AND DUSCUSSION}

\subsection{Crop Field Distribution in Rainy Season of 2007-2008}

Fig. 3 shows the crop allocation maps during rainy season of 2007/2008 at each study site. The background of this figure is ALOS/PRISM imageries. The upper figure is site A, the middle is site $\mathrm{B}$ and the lower is site $\mathrm{C}$. Each colour corresponds to each village. Dots correspond to households' distributions and rectangles are crop areas at each village. The general trend of the crop field allocations was different at each study site in comparison with the results of household survey, DEM analysis and topographical characteristics. As topographical characteristics of crop fields, it is confirmed Site $\mathrm{A}$ is located at very gently sloping area with a slop of 1-3 degrees, site B is sloping area with a slop of 8-15 degrees and site $\mathrm{C}$ is gently sloping area with a slop of 3-8 degrees, respectively. Mountain ridges and small valleys are located at site B and C. The terrain in site A is basically flat and the soil is more fertile than site $\mathrm{B}$ and $\mathrm{C}$.

Almost crop fields are distributed along the mountain ridges and the gentle slope of hill in site C. Crop fields in site B are located around the very steep slope of hills.

In order to understand the cropping pattern at each site, we calculated the ratio of each crop field area against whole crops area. Total area of crop fields in site A is 123.39 ha, site B is 101.63 ha and site $C$ is 146.19 ha. We confirmed site $C$ as to be the largest crop area and site $\mathrm{B}$ as to be the second largest. The cropping pattern in both site B and C is almost same. The cotton fields as cash crop were occupied about $10 \%$ or more in site B and C. The ratio of maize fields in site B and C were over $75 \%$. On the other hand, cotton ratio of site A was $40 \%$ or more and maze was $50 \%$ or more. As explained above, the cropping pattern of site A was confirmed to be different with site B and C. And double cropping is the common cropping pattern only in site A.
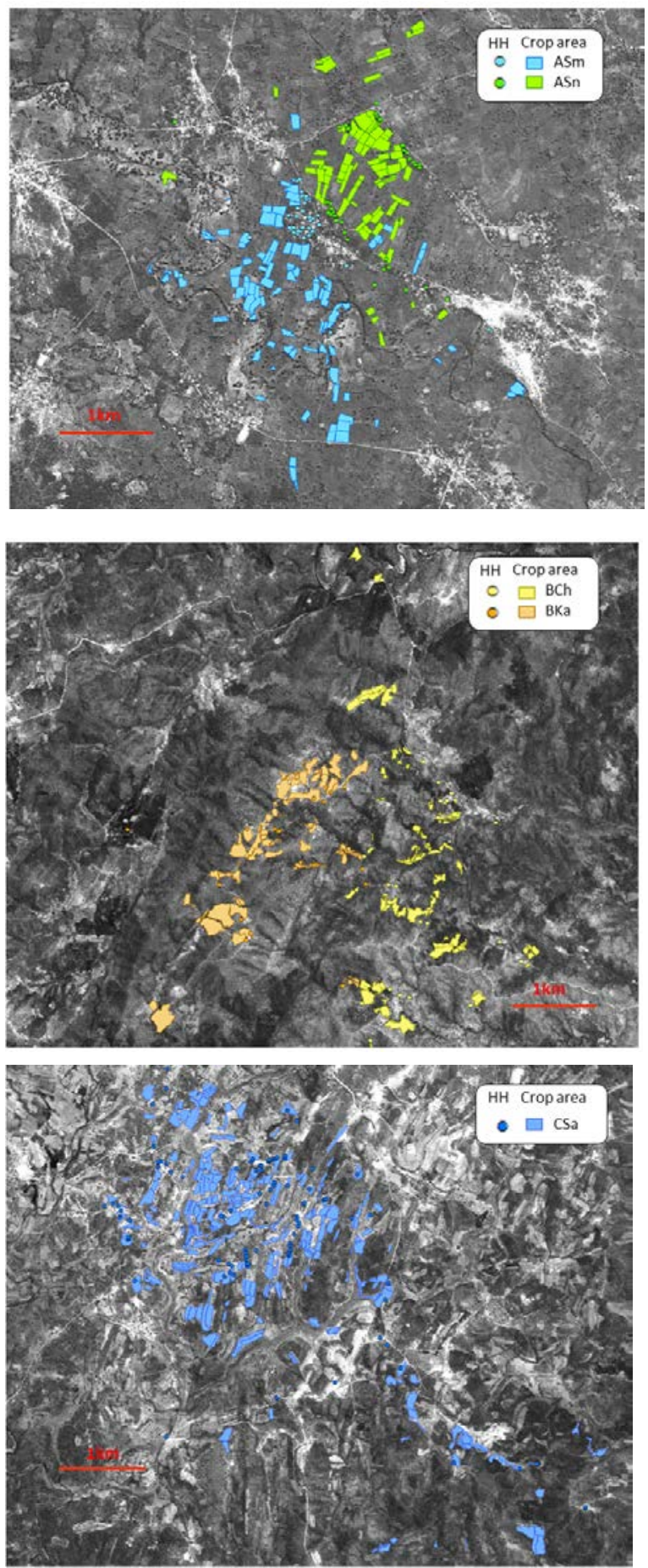

Fig. 3 Crop Field Distribution in site A (upper), site B (middle) and site C (lower)

\subsection{Damage Assessment of Heavy Rainfall Disaster}

As the damage assessment of heavy rainfall in December 2007, we investigated damaged area distribution with area, what kinds of crops were damaged in order to know which site was most affected. In total, about $20 \%$ crop fields with 67.64ha against whole crop fields with 371.20 ha in the rainy season of 2007/2008 were damaged. Almost $80 \%$ of whole 
damaged crop fields were occupied by maize fields and $16 \%$ was cotton fields. This damage seems to be serious for villagers to keep their daily life because maize is staple food. As detailed degree of damage, we calculated the area and ratio of damaged fields at each village. The most severe damaged village was ASn of site A. In ASn, 38.8\% with 22.21ha of whole crop fields with 57.23ha were damaged. Second severe was BCh in site B and its ratio was $32.9 \%$. Only 3.5\% with 5.16ha of whole crop fields were damaged in CSc in site C.

In general, more than $80 \%$ of damaged fields were maize fields at all villages except ASn. $44 \%$ of whole damaged crop fields were cotton fields and $53 \%$ was maize fields only at ASn.

Regarding to households with no damaged, only 4 out of 36 households were not damaged in ASn. Its area was only $1 \%$ with 0.37 ha of whole non-damaged crop fields. Only 2 were households with non-damaged crop fields at both BCh and BKa, they were less than $5 \%$.

Accordingly it was confirmed most of households' crop fields were damaged at villages except ASm and CSa.

On the other hand, regarding to households with damaged fields with more than 50\%, 4 households' crop fields out of 36 households in ASm were damaged seriously and 15 out of 38 in ASn, respectively. 7 out of 23 households were also damaged in BCh and 6 out of 15 in BKa, respectively. No household was damaged in CSc. As we consider this summary by the conditions of sites location, number of damaged households are increasing from upper terrace in site $\mathrm{C}$, middle escapement in site B and lower terrace in site A by turn. We concluded that a village in site $\mathrm{C}$ had constructed at stable land since old years. Consequently we focus on the damaged maize fields and their recover as villagers' coping strategy after heavy rainfall.

\subsection{Coping Strategy after Heavy Rainfall Disaster}

We investigated cropping pattern change for damaged crop fields after heavy rainfall by comparing temporal crop allocation maps. In this case, we focused on the damaged maize fields. As the trend of maize field utilization after heavy rainfall, more than $50 \%$ of damaged maize fields except ASn were abandoned. About $58 \%$ of damaged maize fields were abandoned in ASm. ASn was only 15\%, BCh was $87.7 \%$, BKa was $69.2 \%$ and CSc was $64.2 \%$, respectively.

The cropping pattern of only ASn is different with the other villages: both maize and cotton double cropping before heavy rainfall. The cropping pattern in ASn is still different after hevy rainfall: the maize cultivation was restarted at $80 \%$ of damaged maize fields in ASn. We estimated one reason why this difference was occurred in ASn, the cash crop was not only maize but also cotton only in this village, so that they had a different alternative of livelihood. In CSa, cropping was shifted to dry maize or sweat potato cultivation.

On the other hand, we also investigated changes of the way how to obtain cash at each household before/after heavy rainfall shock. Fig. 4 shows the comparison of cash obtaining ways before/after heavy rainfall shock at ASn and CSa. In this case, we focused and compared on Asn as most severe damaged village and CSa as smallest damaged village. In ASn, cash obtaining ways mainly consist of selling maize, cotton and piece work before heavy rainfall shock in 2007. However selling maize was disappeared and it was changed to selling animals in 2008 after heavy rainfall shock. The other ways such as selling cotton, vegetable and fish was increased. The piece work was also increased. It seems that existing ways has strengthened instead of maize production damages. In CSa, ways consist of selling animal, maize and vegetable. And the other is piece work. These four ways combination was not changed after heavy rainfall shock. However the balance of combinations has slightly changed.

\section{CONCLUSION}

Through this study, we investigated impact of environmental variability on agricultural production and analysed factors determining the ability of households to recover from environmental shock in the case of heavy rainfall shock which occurred at southern region of Zambia in 2007. We confirmed the way to strengthen resilience of subsistence farmers as follows: it is necessary to prepare variable crops and emergency food stock with not only diverse but also composite social institution. The resilient society seems to be the society with insurance such as adaptation ability against environmental shock caused by climate change. From the agricultural production point of view, both diversity and yield ability are also important. For strengthening subsistence farmers' resilience, strengthening of agricultural productivity, diversity of cropping pattern, non-crop agriculture, diversity of livelihood, improvement of nutrient status and construction of social network are important and they are organically accumulated and integrated.

In this study, we investigated villagers were destroying forest as important natural resources and selling them instead of cash crops after the extreme shock by climate change. This destroying and selling of natural resources is regional environmental issues. However, if these kinds of regional issues are accumulated in whole poverty countries, it could become to be global environmental issue. Accordingly, the poverty provision as one of solutions for global environmental issues is required under the collaboration with developed countries, today. 


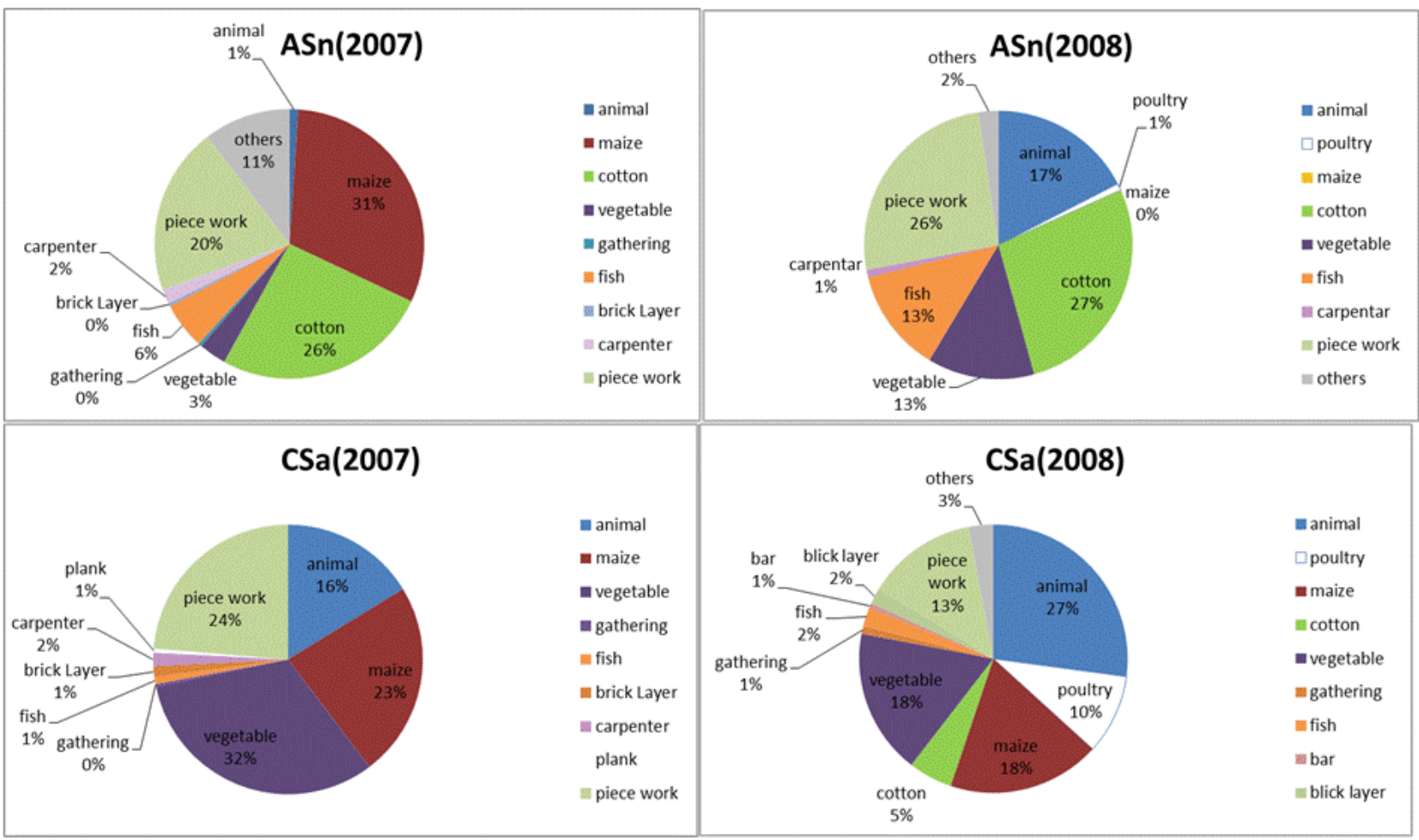

Fig.4 comparison of cash obtaining ways before/after heavy rainfall shock at ASn and CSa

\section{REFERENCES}

M. Yamashita, H. Miyazaki, Y. Ishimoto and M. Yoshimura, 2010. Multi-temporal and Spatial Data Integration for Understanding the Livelihood in Village Level, International Archives of the Photogrammetry, Remote Sensing and Spatial Information Science, vol.XXXVIII, Part 8, pp.827-830.

C. Umetsu Edt., 2011. Vulnerability and Resilience of SocialEcological Systems -FY2010 FR4 Project Report, InterUniversity Research Institute Corporation, National Institutes for the Humanities, Research Institute for Humanity and Nature, Kyoto,pp.14 